\title{
Exquisite Attention: From Compliance to Production
}

\author{
SUZANNE DE CASTELL \\ Simon Fraser University
}

Attention has been a focus of much of the work I've done over the last several years, and in particular the 'attentional economies' (Lankshear and Knobel, 2002; de Castell and Jenson, 2005) involving teachers and learners in both classroom-based and non-formal educational environments. What has become very clear is the need to distinguish between attentional behaviours, and other, more complex, more demanding and more generally 'educative' kinds of attention. I'm drawn to the idea of 'exquisite attention', (Lather 2007:16) and particularly interested in the pleasures of attention, as well of course as its productivity. Maybe its exquisiteness, a pleasure of attention, can be related to its productivity. We have long known that attention can be productive indeed, all by itself, seemingly. Consider the Hawthorne Effect, notorious among researchers---as soon as I begin to pay attention to you, you get better at what you are doing. Having other people pay close and careful attention to what you are doing often helps you do it better. But I want to argue that exquisite attention can never come from other people, but only from ourselves. And I want to set out some ways to see an ethics, an epistemology and a pedagogy in this small claim. Probably many of us gain considerable enjoyment from having other people pay attention to our work, but I'm going to argue that this is a mistake, and a misleading one, in several important ways.

Well, I immediately need to qualify that bold assertion. The attention of others can be enormously pleasurable for children, by whom we are commanded to "watch me!" on waterslides and baseball fields, in the bath, swimming pool, splashing in puddles, or making toast. Pretty much anywhere, anytime is right for kids to require our attention. Even with children, however, there is another, far better kind of attention adults can and do pay, but it's not actually attention paid to THEM, but to a shared attentional object. One of our research sites, the Vancouver Art Gallery, gave us a perfect example of attention of this kind. At one "Super Sunday" session, where kids and parents go to one or more selected exhibits and then co-participate in a workshop structured by VAG educational staffers to engage more deeply and creatively with some aspect of the works seen, a young boy, about 4 years old, was recreating his own version of an installation, a video of the construction of a spiral jetty. Using popsicle sticks and little bits of green felt, paint, scissors, tiny plastic trucks and glue, Mum watched and encouraged and chatted as her young son considered what to construct and how to put his creation together. We use videotape extensively in our attention studies, and we have a good deal of rather slow footage---but nothing quite a slow as this. People joke about 'watching paint dry', and this event was close to that exciting: boy selected a popsicle stick and fixed it in place, at an angle, perhaps for his little truck to drive down. Then, for no obvious reason, he planted a large globule of sticky glue at the top end of the stick. And he and Mum watched. They just sat, completely quietly, and watched as the glue began its meltingly slow downward slide. Mother was WITH boy, was attending fully, but the object of their joint attention was glue on a stick. Suddenly boy squealed with delight, "Oh, will it go down? Its go---iiing..." and neither moved, as if extreme care was needed 
prevent any interference with the progress of the drip of glue. Minutes passed. "Will it go?" asked Mum, eyes fixed on the drip? "Its GO-IINNGG!" Exclaimed boy, with real glee and excitement. Well, enough of that thrilling tale---the point is that intense attention was being paid to what, in most classrooms, would be called either 'nothing' or 'timewasting', but what ELSE was going on in these scene of exquisite attention? First of all, Mum was fully present to boy, rewarding and reinforcing their relationship and their engagement with the gallery's works seen earlier. Second, Mum was fully present to the object of their joint attention, legitimating boy's attention as rightly and usefully focused (on the glue drip), enacting and ostensively defining for boy what 'paying attention' involved and looked like. Third, (this is pure speculation on my part), boy was 'thinking', but not of course capital T school-sanctioned "Thinking", about what he had seen, its movement, (trucks bring and dump loads of fill around in a spiral to create the jetty) and his own design plans for the sticks, trucks, bits of paper and felt as he contrived his own 'interpretation' of the exhibit.

I thinking that not just this exquisite kind, but indeed all kinds of attention-seeking and being gratified by the attention of others is more than OK for kids, and it's probably even essential for their development. But if we, as adults, do what we do better because of other peoples' attention to us (and encourage our students to do better because of our attention to them), we are not actually the agents of that improvement, which is after all dependent upon those other people. We are not then cultivating agency for ourselves or for our students, we are cultivating dependency. This kind of attentional economy---I profit from your attention, and endeavour to receive more of it than I give---- is not empowering, it is not autonomy, it is the cultivation of dependence and derivativeness, not originality or agency. What's not up to snuff, from an educational standpoint, in these cases, is the character of the object of attention. Of course we and our students are all wonderfully worthy characters, but attending to someone do something is not the same as attending to the thing done. When we teach and learn, it is not to the teacher or the learner that the attention needs to be paid, but to the object of attention and intelligence, to the thing being done.

Most classroom work is still, technological revolution notwithstanding, done in writing. But the kind of writing classrooms mainly require engages a pale, thin, bloodless and passionless exercise of basic literacy, and only very rarely is this the quality of writing about which there is any justification in getting lit up.

Franz Kafka urged that "A book must be the ice-axe, to smash the frozen seas within us"; Monique Wittig spoke of 'terrorist discourses' and of powerful writing as a 'war machine, a 'Trojan horse'. Where is the passion, the power and the terror of books and writing at school?

What these writers shared, which most of us, and even more of our students, do not, is an appreciation of the awesome weaponry that literacy affords us. Instead of this highly conscious, acutely aware and informed and skilled relation to writing, in education we mostly presume writing to be a transparent window on to meaning and truth. My research students, for instance, have always to be disabused of the notion that if I ask someone a 
question, that's research; if they answer me, that's data. Teachers talk to students about "what the book says", while students pursue various proto-literate practices such as word barking---parroting back, without any understanding of it, the specific term that the teacher is request, and copy matching---finding a set of words that closely resembles the wording of their particular "comprehension question", mistakenly so-called. What is going on in these cases illustrates a profound and pervasive failure of attention----a failure of teachers, as well, when they concentrate on the surfaces of language, and don't actually either properly listen, or thoughtfully interpret.

\section{C: Why do they, pit vipers in a pit? \\ T: How about, "Why do they call the snakes pit vipers?" C: Why do they call the snakes pit vipers? T: There you go! Good for you.}

In this transcription of a teacher/student exchange (Palincsar and Brown, 1984:138, in Wertsch 1991:142) that has become one of my favourite examples, Palicsar and Brown document an instance of 'reciprocal teaching' in which the teacher helps a child to learn how to ask good comprehension questions of a text about 'pit vipers'. It illustrates, for me, nothing like that. Rather, it stands as eloquent testimony to our abilities as teachers to completely miss what it is our students are paying attention to, and to miss, thereby, the often considerably more valuable educational engagements than we may have in mind for them. When we READ the transcript, we might suppose the child was not clever, was mightily confused or just not paying attention. But I'd argue it's the teacher who is inattentive, does not listen to what the child is saying, and does not consider the depth of what is meant. Like a glue drop making its leisurely way down a popsicle stick, children's strange questions may conceal great depths of meaning and educational potential. That a child's pronunciation of 'put' might, in some region or to some ears, be indistinguishable from 'pit' is only a sufficient explanation of this misapprehension if focusing on what the teacher is saying and doing is what learning is all about. And so the student is 'coached' to produce the requisite comprehension question "why do they call them 'pit vipers', when his own question "why do they put vipers in a pit?" can take us a long, long way further than helping children to talk like little teachers. In a very similar case, a videotape of a young teacher doing a 'unit' on 'bears', the object of the lesson is to get children to generate lots and lots of different characteristics of bears. The teacher begins: "Bears are furry. Bears are growly. Bears live in the woods". And so on, and on, as one child after another pipes up with characteristics: "Bears are hungry, Bears are cuddly, Bears have claws"...and as the list grows, with the teacher nodding and murmuring approvingly to each child's contribution, the array of bear features becomes ever more incongruous and troubling. Regardless, every contribution is accepted warmly--so bears are also fat, scary, nice, lazy, warm, fierce... until one small child pipes up "people kill bears". An awkward silence, then teacher assents, well, yes they do but...(brightening up), "What else can we say about bears?"

What we see in these cases are not literacy practices---though each of these cases, had they been coded by a reading researcher, would be coded as a different kind of literacy instructional practice. What we see in these cases can be generically grouped as practices 
of compliance. And attentional compliance is a not at all exquisite, in fact, it is stultifying.

If we teach by having students focus on what we direct them to focus on, all we can expect in return is what is called 'continuous partial attention'--- We've all seen this, and we all do it. Students who are simultaneously immersed in playing their DSs, listening to their ipods, facebooking, concealing one-handed pocket-texting, twittering, online chatting, etc at the very same time as they are correctly answering teacher "comprehension" questions like "How many times did Wilbur fall off the truck?" or "What colour were the flowers that David took to his grandma?", or "pre-reading" questions like "Why do you think someone would want to live in the woods, far away from other people?", "What do you think it would have been like to be hiding for years in an attic room"? They are able to do this because what we are asking of them is educationally bankrupt, insignificant and entirely undemanding of even the most modest level of knowledge, skill or intelligence. It's as if the whole lot of us have fallen asleep at the wheel, and we are being taken off, further and further from any kind of educationand any kind of literacy---worthy of the name.

In our studies of attention, the one thing which stands out most clearly is that teachers do not know whether or when students are paying attention, and perhaps more importantly they very often do not know to what, either. Every teacher we spoke to or observed equated attention with direction of gaze, themselves attending to the object of student attention. If students were looking at their books, they were paying attention to their reading; if students had 'eyes front', on the teacher, then they were paying attention to the teacher. But this, as we know in our hearts, is utter nonsense. Behavioural conditions of bodily stillness combined with an absence of vocalization and heads inclined in the prescribed direction, with eyes following the target object, constitute compliance, not attention. We can of course make people perform attentional behaviours, but we cannot make them pay attention, nor can we know when they are doing so. Attention is incredibly interesting because, like meaning itself, it's something over which outsiders have no control, and to which we have no access. People have a vast repertoire of ways of not attending while looking like they are, and in the absence of any way to actually know whether someone is attending or not, teachers may routinely accept the bill of good without the goods themselves being delivered--- demanding, and being satisfied with, compliance---with behavioural indicators plus the kind of surface-level monitoring that we call 'continuous partial attention". The truly dreadful outcome of this deeply habituated institutional practice is that, lacking any way to deny that students who are behaviourally compliant are in fact paying attention, and compliant themselves to the educationally ungrounded but politically driven requirements for 'objective assessment' and 'accountability' teachers have become inured to an insidious 'instructional exchange' which is an insult to them and their students alike. We're not talking about students failing here. We're talking about students who pass, who succeed, who complete grade after grade, who graduate and yes, unhappily, who go on to university. The reason students can succeed in their classes, seem to be following along, seem to be learning because they are in fact getting the 'right answers' is because we have, accordingly, reduced our intellectual demands to match our behavioural demands---we ask only for brute behavioural compliance, not for intelligent attention. The kinds of questions we are 
used to regarding as 'comprehension questions' are absurdly low level, as are the majority of the things we ask students to do---superficial fact-gathering and stating, opinion pieces, formulaic and clichéd expressions of 'critique', shamefully literal, completely artless descriptions of holidays and pets and seasonal events, and, when we get really hard core, the inevitable 'compare and contrast' exercises. That the levels and kinds of intellectual engagements we require of students are so abysmally low-level may surely be a large part of the explanation for the widespread student disengagement and underachievement at the secondary level which is only now, after how many decades, finally being acknowledged, never mind the painfully inept and equally disengaged writing and thinking we have to contend with once they get to university.

But attention is not compliance, and we will do our jobs better when we stop treating it as if it were. Attention can't be coerced, and if it is truly to be paid by students, it needs to be earned, that is attracted, directed, focused, held, by teachers or, better yet, by students and teachers themselves, both attending to their respective, sometimes common and sometimes different forms of engagement. This is not something we can compel.

\section{He will not verify what the student has found; he will verify that the student has searched. He will judge whether or not he has paid attention...demand from his student that he prove to him that he has studied attentively. Is this insignificant? Think of everything the demand implies for the student...}

Ranciere, The Ignorant Schoolmaster (1991:31)

But the news here is not all bad. We can never know whether or to what anyone else is paying attention, to be sure, though we can, in the ways Ranciere (1991) points out, establish whether or not the child has paid attention. About full and present attention, we can only know our own case. We can only know to what it is that we ourselves are attending, and how, and why. If I am presently at the front of a room of people, and I say "all eyes front, now pay attention", doubtless many eyes will face front but I have no idea, in fact, I would hate to even imagine, WHAT it is to which each person is paying attention, or whether they are at all. But I know about my own attention, and I can be accountable and responsible for that, and I can use what I know about attention to help my students learn. And that, luckily for us, is more than enough to help us do our jobs better.

For our attention studies we developed and are using something we call MAP"multimodal analysis program". MAP is an application we developed so we could study educational interactions multimodally. One thing we had come to understand through our initial fieldwork across formal, and non formal learning environments was how much of what happens in teaching/learning interactions is done wordlessly---through gesture, tone, proximity, movement, through tools and symbols, through non verbal vocalizations, exclamations, sharp or slow and measured intake of breath. And when we began to look at educational researchers who were using images and video data in their analyses, we found an even more interesting thing: all the data, linguistic or non- were coded by 
reference to language---in other words, whatever else was being seen and heard, it was all treated as an accompaniment to what was being written or said---interestingly, when the visual record contradicted the verbal one, the visual record was overridden and disregarded, with the linguistic record being in every case taken as authoritative. That was why we resolved to build some software that would de-privilege language and allow us to look at the rich complexity of factors which together make up an educative interaction.

The methodological affordances of digital audio-visual technologies support a retooling which draws qualitative research into closer alignment with the broader epistemic transformations brought about by the widespread integration of digital technologies into our everyday lives. Now that print is only one of many modes through which meaning is produced, communicated, and shared, we are invited to rethink the notion that our means of mapping and understanding the social must "always be writing," and we can pursue research methods of inscribing, analyzing and sharing ethnographic knowledge that are similarly multimodal.

A tool for the multimodal analysis and coding of verbal and non-verbal communications preserved in audio-visual data, MAP enables users to mount and play a selected audiovisual clip above a series of channels, similar in look (and, by extension, in how it's read) to a musical score.

Each user-defined channel in the score represents a distinctive communicative mode and/or hypothesized source of significance in the clip: one participant's immobility, another participant's laughter, episodes of group laughter, sudden or sustained instances of quiet, or shifting physical proximity between participants, for example. MAP is ideal for watching glue drip down a popsicle stick, and for seeing exactly why the quality of attention paid to that otherwise entirely UN-engrossing event might be very important to understand.

The beauty of this tool is in fact its meaninglessness, or, more precisely, its semantic arbitrariness: there is no content to this instrument. In itself, it's completely empty, devoid of any significance, a set of functions---a bit like zeros and ones or, before that, the alphabet. That means that whatever meanings it can convey are entirely at the disposal of the user, and it also means its ability to convey meanings is not limited. As users add events to each differently-coloured channel, a semiotic score emerges which charts communicative actions across the multiple semiotic layers a user has identified as significant. Using MAP, researchers can annotate complex interactions among participants and draw attention to significant instances of gestural, verbal, and physical exchanges, and to otherwise unobservable inter-relations between and among them. One such "semiotic score" is shown below. The multimodal coding of video data means researchers can not only attend to a range communicative modes, but also to how these communicative modes interplay, converge and are coordinated over time. 


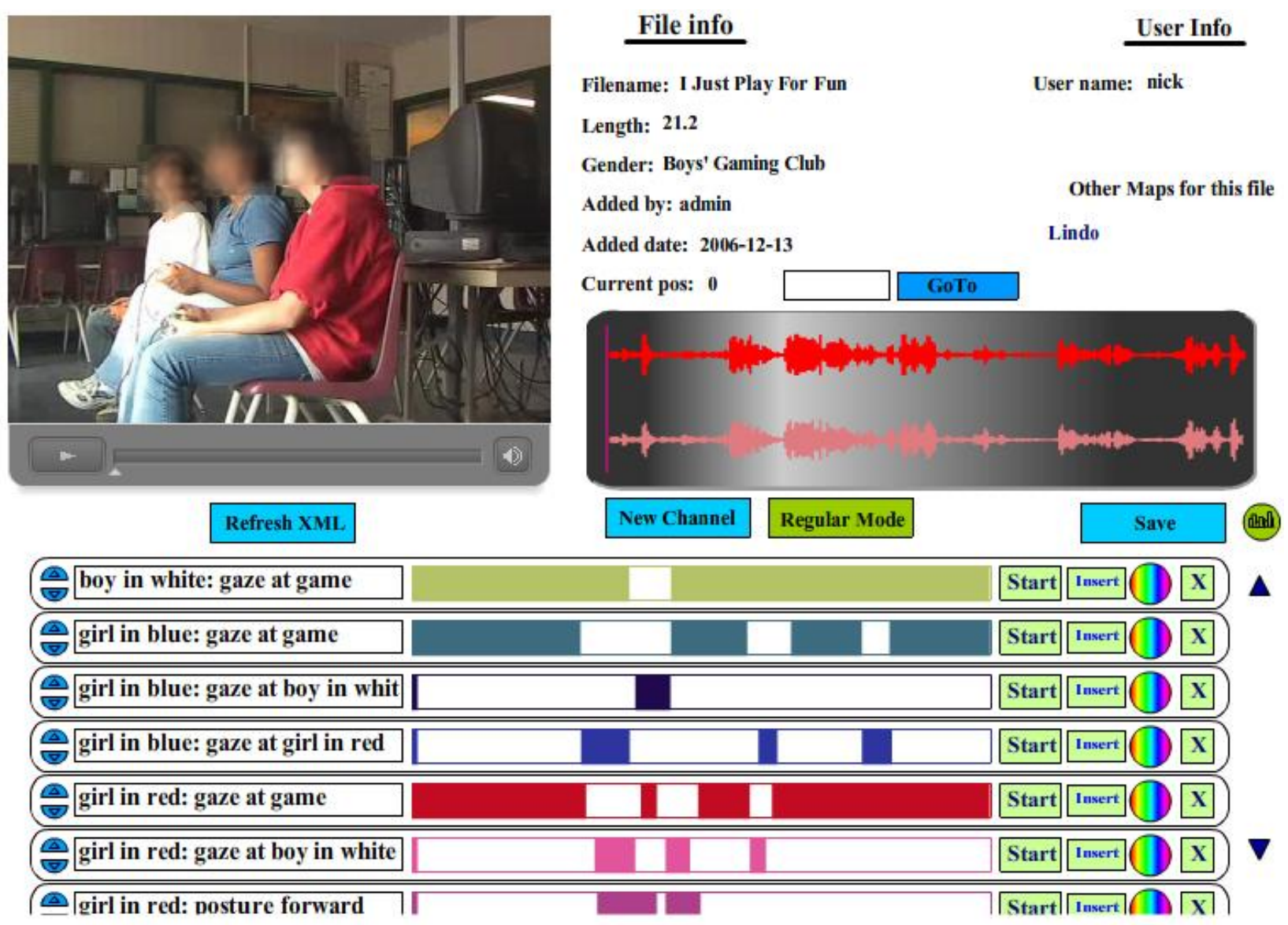

\section{A screenshot of the current MAP interface.}

In the above clip, for example, tracking attention based on gaze both 'captures' and preserves an event for more detailed scrutiny across multiple modalities than text can afford. This both exceeds the profound epistemic shifts enabled by the stability of print relative to the impermanence of embodied speech (Goody, 1977), and as well suggests particular new hypotheses about what ELSE is going on that is not the object of direct sustained vision (in the above case, hypotheses about gender and videogame play).

As importantly, and we are beginning to think perhaps more importantly, MAP allows for, and indeed invites, multiple interpretations of the same interaction by differently positioned observers. In making visible the ways we conceptually organize and make meaning of audio-visual data, MAP affords a degree of researcher reflexivity not readily available through primarily textual techniques of analyzing and reporting on ethnographic research. A means not only for coding an interaction, but for representing the coder's own process of attending to what she deems significant in that interaction, MAP allows researchers to work towards a critical understanding of not only what, but how they attend to events and read and "code" their meanings. The iterative and intensive process required to "map" an audiovisual clip, of identifying channels and then plotting instances across these channels, thus becomes a process of "mapping" not only ethnographic 
meaning, but the meaning-making process itself in ways that enable researchers to "reflect on their own subjectivity" (Sarah Pink, 2006, p. 10).

We are using the very grand name, digital hermeneutics, to refer to the ways that researchers using MAP can access and compare diverse interpretations of data, bringing qualitative research into closer alignment with the broader epistemic transformations digital technologies have ubiquitously wrought in our lives. We think that MAP helps us pay better attention to the possibility, central to the very idea of a humane social science, of systematic, relatively well-structured variations in the objective perspectives (Mead, 1932) of differently located interpreters of a shared perceptual event. MAP thus provides an exceedingly useful tool for visualizing, sharing and analyzing data and supports a profound and long overdue re-conception and representation of validity in ethnographic research.

\section{Evidence, Validity, and Rhetorical Responsibility}

We had 3 main goals in developing MAP: first, to generate nuanced and fine-grained analyses of audio-visually recorded communicative interactions, integrating textual as well as audio-visual data convergently, in a way that could makes evident, public, and objective the functional relationship among multiple modes of expression. Until now, researchers have been unable to identify and represent objectively the ways in which, and the extents to which multiple modes of communication and expression work together, coconstituting human communication and interaction in ways far more complex than our research tools have thus far allowed us to see. Our second goal was to create a comprehensive online database where a global community of social scientists engaged in audio-visual research could store, organize, code, and share their MAP-based analyses. Our third goal is to chip away at conceptions of validity which have not served humanities and social sciences well at all, and which have systematically undermined our abilities to generate the kinds of relational analyses upon which human social scientific work depends. It is not despite generating competing accounts of phenomena, but indeed precisely BECAUSE of it, that we can demonstrate patterns and regularities in the ways identity, context, interests and positionality shape and constrain attention, perception and interpretation - and we can show that this inter-rater DIS-agreement does not make alternative interpretations less objective, nor less valid, but indeed far more so. And (though this is another paper altogether) this is something we have all always already known: that there is not one truth, one right way, one correct perspective on any phenomenon---but we have for too long, and as McLuhan (1964) reminds us, far too myopically, deployed the various dictatorial affordances of text to both conceal that knowledge from ourselves, and to enforce its concealment from and by others. Qualitative researchers have long needed a way to make both objective and at the same time relational, the phenomena they examine. MAP provides a technologically-driven means of beginning to re-mediate conceptions, criteria and practices of 'evidence-based' research, and to foster thereby a far greater "rhetorical responsibility" among researchers interested and/or currently engaged in audio-visual social science research. Combining visual representation of multimodal data with well-structured computer-supported researcher interaction/interpretation techniques, enables an integration of "situated" (and 
thus context-relative) human judgment with objective, quantifiable and fully comparable accounts ("semiotic scores") of publically shareable data, in the form of audio-visual documentation of social-interactional events.

By charting and visually representing the co-ordination of multiple modes of communicative interaction across time-literally "mapping" audio-visually recorded micro-interactions - MAP requires its users to confront and work through their own meaning-making processes: to become accountable for what and how they see, and what sense they make, of the same piece of audio-visual data. With the MAP tool as a central component of a broader online infrastructure where researchers can store, organize, and code their own project's audio-visual data, as well as collaborate with other researchers across institutions and disciplines through sharing their analyses of and insights into audio-visual research, MAP creates grounds for a profound reconstruction of our conceptions of evidence and associated practices of "inter-rater reliability," informing our conceptions and practices of how "evidence-based research" is re-mediated by new and emerging digital tools. Reflexively, moreover, MAP can inform and advance rhetorical responsibility not only on the part of researchers towards their data, but across and within communities of practitioners.

To the extent that it cultivates rhetorical responsibility on behalf of its users to their research data, and also, potentially, to a global audience of fellow practitioners, we see in MAP a means of working towards what Donna Haraway some time ago called "accountable positioning" (Haraway, 1988: 590) a mode of scientific exploration in which the researcher confronts and makes public her own meaning-making processes, rather than assuming the "view of everything, from nowhere" that Haraway says has, to its detriment, characterized Western science for centuries.

By enacting these epistemological and ethical considerations around the "doing" of transdisciplinary work, then, our aims are not simply to integrate new media into conventional approaches to knowledge-building, but to challenge our commonly-received notions of what counts as "knowledge", "truth", "facts" and "evidence" as more and more social practices at work, home, play and school are re-mediated by technologies which fundamentally displace the deceptively monological authority of text.

This affords us a more purposeful way to take up this paper's earlier denunciations of the facile and superficial character of our 'curriculum' and of the intellectual (as well of course as the impoverished social and ethical) demands we place upon our students. Armed with good reasons and objective evidence, we can reconceive attention as an intellectual engagement and not (or not merely) as a behaviour, and understand perhaps a little more about intersections between ethics and education, between attention and intelligence, and about the pleasures of attention.

Pleasure is particularly interesting to me because, complementing the attention studies just discussed, I work as well on educational media, and specifically, on digital gamebased learning. (de Castell and Jenson, 2003; 2006; 2007; 2008) One aspect of that work is to thoroughly challenge the traditional dichotomy between learning and leisure, 
between education and entertainment, between work and play. In this work (all done collaboratively with Jen Jenson), we always begin by reminding people that all we are doing is re-fusing a distinction which, historically, is a relative latecomer on the educational scene. Early greek child-rearing, as we know, took place in gymnasia, where boys played games, learned to sing, dance, play the lyre, ride on horseback, and have contests of wit, skill and strength---all of which we nowadays classify as play. In Latin, the word 'ludus' meant both school and game or sport, both learning and play. In fact our first digital game was called 'ludus vitae', which of course means both school of life, and game of life. Why this matters---lots of reasons but I'll mention just a couple--pleasure and its importance for deep and engaged, and play, and its importance for risktaking, exceeding one's present accomplishments and prior limits learning, and the role of both pleasure and play in intensifying both attention and intelligence. Briefly, an axiom of our work is that (after Gilbert Ryle, 1949) intelligence is adverbial to attention. We are not intelligent, we DO SOMETHING, for instance we attend to something, intelligently, or not. Another way of putting this is "whatever a child is paying attention to (whether or not you think it is important or valuable) THAT is where her intelligence is at work. And on our own view, intelligence is often most fully and productively at work, in play.

OK, so where this is leading is to the fact that we have culturally lost something of enormous value to us educationally, and that is the pleasure in intellectual engagement, and this is very much in the same vein as the power and terror of writing, referenced at this paper's outset-- the actual, not metaphorical, JOY in learning, the exhilaration we see in fully rapt attention. Anyone who does sustained intellectual work will know that whereof I speak. It's the heart-pounding, sweaty-palmed, can't sit still excitement of seeing ones ideas (or pencil lines, or brush strokes, or video-clips or numbers or musical notes), come together into a pattern which, in that moment, has an almost unbearable beauty. It's the times when you almost can't write the next words, but you can't, either, keep from writing them and you are amazed, completely amazed, at what they are coming into the world as. This is the time people used to refer to as 'the muse taking over'---as if the picture paints itself, the equation is solving itself, spinning out its proof before your eyes, the essay is writing its own conclusion, the story characters are making themselves up in all their gloriously detailed depth and complexity. Of course, as classical scholar Eric Havelock (1963: 101), in his discussion of this trope of the 'muses' pointed out, this experience is actually just the result of achieved knowledge and skill reaching its breaking point, its point of overflowing beyond its own creator, or so it often seems. And 'inspiration', of course from the greek, 'spiro', meaning 'breath', is not the breath of the gods or muses, but that magical inflation of our intellect that results from our having spent enough time 'breathing in' the work of others from whom we have, joyfully and by this point almost unwittingly, learned. Conversely, we can wait around with blank pages before us, drink plenty of wine and listen endlessly to Coldplay or Stravinsky, and never get 'inspired' because we are scarcely breathing at all, taking in the thinnest of de-oxygenated air, there is no sustenance here, so there is nothing to in-spire.

This, I argue, is the situation most of us, along with most of our students, are in. We have learned to regard learning as labour, and we are suspicious of pleasure: 'unauthorized' 
laughter in class is, typically, a symptom of bad behaviour and a sure sign of being 'off task'. Moving, vocalizing, using one's body, touching others, staring at a page for too long, holding a brush in the air for too long, watching the paint dry... all these are routinely 'corrected' with admonitions to 'get back to work'. What an enormous loss for education in these admonitions! We probably learn far more about how a child is thinking, and what he or she can do and understand, if we pay close attention, not so much to them and to how well or badly they attend to and reply to our "comprehension questions", as to what and how they are, as we say "playing at". Eleanor Duckworth (2001) tells us that if you want to know what a child is thinking, pay attention to what the child is paying attention to. That's very different from asking us to get children to pay attention to what we are 'teaching' them.

\section{Production Pedagogy: The Importance of Making Things}

The thing is an always available source of material verification: the ignorant examinee's art is to "bring the examinee back to a material object, to a thing that he can verify with his senses"...verifying, not the child's knowledge, but the attention he gives to what he is doing and saying.

Ranciere, The Ignorant Schoolmaster (1991: 32)

I do want to just say a bit in closing about a pedagogy implicit in this perspective on attention: "production pedagogy". For a while now we (Jenson and de Castell, 2004) have both been rather disappointed in the routinized, low level and intellectually thin work essay assignments students were producing in our classes. So we started to assign non-text-driven and specifically non-ESSAY-driven assignments, using the unfamiliar tools and grammars afforded by digital technologies. We do not give students many instructions----we simply ask them to build a tool that they can use in their own educational or other work----it needs to be of use to THEM. Whether in a curriculum course, or a game studies course, or an educational technology course, or even an educational theory course---we simply require production of a tool, something instrumental with a clear use for them. That shifts things, and they shift a LOT. The first thing that happens, of course, was students feel overwhelmed by the task, and they continue to feel overwhelmed until they are able to pare down the task to be something they can actually achieve. Important pedagogical lesson \#1: bring students directly into contact with what they themselves are actually able to accomplish, recognizing both how little that is, and, at the same time, how important and how sufficient that can be. Enough of asking the class what they would do if they were in charge of the nation's business, or who they would save if a lifeboat didn't have room for everyone, or how they would set about finding a cure for cancer----we are forever asking students to talk about things they know nothing about without, however, requiring them to even come to terms with what they would have to know were they to know enough to do what we are asking them. That we have produced a culture of mini megalomaniacs is probably obvious from the kinds of public policies we now have, or from the global economic collapse, or from the critical environmental breakdown we have to deal with because people took control over things whose enormity and complexity they had no understanding of. The resurgence of the local in every part of our consciousness is well-served by production pedagogy's way of 
confronting students with their own limited---but no less educationally fruitful--knowledge and abilities. What happens when you do this kind of work is---this is about in week 4---the remarkable phenomenon we call "the professor has now left the room"----its about week four when we discover we can simply walk out of the class, for literally hours at a time, and the work continues unabated. What does this mean? Well, one important thing it means is that we do not have a motivation problem, and we have no need to call the students to compliant attention on us or on the books and assignments we give them, they are already fully attending, they are entirely in control of that attention, their intelligence is fully deployed and what they are doing is neither thin nor superficial nor vacuous nor clichéd. They are making something, and out of the making, comes engaged thinking about a difficult challenge. Out of engaged thinking about a difficult challenge comes considerable intellectual accomplishment. This is significant inversion one to which Gunther Kress (2000:160) draws our attention: we are always being urged to promote critical thinking, and we do this principally by looking at something (usually words) or talking about something, and then talking about what it 'conceals' -media messages, ideologies, stereotypes, vested interests, etc. Those who promote 'projects' and other kinds of hands on work in classrooms normally follow this sequence: (1) critical thinking, then (2) design something based on your critical analysis of other peoples prior designs, then (3) carry your design into production. Our approach following Kress, is to turn that sequence on its head: first, production work, then elucidate and refine the design, in and through the production process (rather like what's called 'design-based research). Finally, we need where most people begin---with critical thinking---. We work like this not just in our pedagogy, but have learned over the years to do our own work this way---we make things (usually digital game-based learning tools, of which we've done several, most recently a baroque music game) and in the process of that making, we chip away at the project's design, we do our research into game-based learning THROUGH the practices of design, and finally, we critique the work we've done, we basically retheorize it, in a species of intellectual work I call 'design-driven theory. One example of design driven theory is a paper on "Ludic Epistemology" (de Castell and Jenson, 2006)--that is to say, on the forms that knowledge takes when it is translated into the form of a game. The work of making our game---in that case, it was Contagion, a 9-level, 3 character, health based role-playing game to teach kids about self care and community health promotion in a pandemic, timely enough these days---and the effort of making explicit this final design generated for us a wholly new range of conceptual questions and some very interesting and innovative answers to those questions. So, in production pedagogy, with its exacting demands and high level challenges which require intense and concentrated attention, production leads to design leads to critical thinking, and not the other way around.

Now I want to tack back again to this idea that we can never know anyone's attention but our own, and what why that matters so much as a basis for both teaching and for research. In working with teachers, I ask them, too, about attention---when they get bored at school, how they get through their days, what they are paying attention to, and its obvious that many teachers, too, can get terribly bored through a good deal of their working day. And why not---it's a bit like seeing Wild Kingdom, then going to the zoo--- 
there's only so long you can look at fat, pathologically under-stimulated lions sleeping under a rock in a corner of their pen. And, of course, its worth noting that some of our disengagement with this zoo scene is a nagging sense of guilt. It's never fun watching things suffer. We KNOW lions should not be like this all their lives, just as we know children should not be so painfully and obviously bored, however actively they 'play around' in class, disturb other kids, make trouble for their teachers, they are desperately under-stimulated, underperforming, needing constantly to be called back to 'protoattentional compliance'. We are not simply bored by their pale, insignificant, uninspired performances of their assigned role of compliant student, we are also naggingly guilty for being the institutionalized enforcers of this deplorable waste of young minds and bodies, of days and months and years that could be so rich and are instead so generally thin, pale, and un-sustaining. What we might instead aspire to are days and weeks and months when we hate to tear ourselves from our work, when we are sorry to hear the recess bell, the lunch bell, the end of the day... when we and our students leave shaky with exhaustion and giddy with exhilaration. These things are possible. WE know they are--- we have all experienced this, and education deserves to be no less than this. THAT is "exquisite attention", but it is not a quality of attention anyone else pays to our work, but a quality of attention we pay, and we help our students to pay, to what we can ourselves produce, whether in writing, or in any other medium of creation, analysis and expression. The challenge is first to recapture this for ourselves, and then try to 'inspire' our students with attention of the same kind - not by making them pay attention to us but by helping them pay attention to themselves. This is exquisite, indeed.

\section{References}

de Castell, S. and Jenson, J. (2003) 'Serious Play,' Journal of Curriculum Studies 35, no. 5 (2003): 1-17.

de Castell, S. \& Jenson, J. (2006). Ludic Epistemology? Knowledge-Representation in Game-based Learning. Proceedings of the International Conference on Computers and Advanced Technology in Education (CATE). ACTA Press.

de Castell, S. and Jenson, J. (2007) Digital Games for Education: When Meanings Play. Intermedialities, No. 9, Spring, pp. 113-132.

de Castell, S., Jenson, J., Taylor, N. \& Droumeva, M. (2008). Baroque, Baroque Revolution: High Culture Gets Game. Futureplay Annual Proceedings. ACM Digital Library.

Duckworth, E. (2001) Tell Me More: Listening to Learners Explain. New York: Teachers College Press, New York

Goody, J. (1977) The Domestication of the Savage Mind. Cambridge: Cambridge University Press.

Haraway, D. (1988). "Situated knowledges: The Science Question in Feminism and the Privilege of Partial Perspective". Feminist Studies, 14(3), pp. 575-599.

Havelock, E. (1963) Preface to Plato. Cambridge: Harvard University Press

Jenson, J. and de Castell, S. (2004) "Turn It In: Technological Challenges to Academic Ethics". Education, Communication and Information, 4, 2/3, pp. 245-67.

Kafka, F: (1904/1977) "Letter to Oskar Pollok, January $27^{\text {th }}$, 1904" in Letters to Family, Friends and Editors. Trans. Richard and Clara Winston. Berlin: Schocken Books 
Kress, G. (2000) "Design and Transformation: New Theories of Meaning" in Multiliteracies: Literacy Learning and the Design of Social Futures, Eds. Cope, B. and Kalantzis, M. (pp. 153-161) Oxford: Routledge

Lankshear, C, and Knobel, M. (2002) "Do We Have Your Attention? New Literacies, Digital Technologies and the Education of Adolescents," in Adolescents and Literacies in a Digital World. Ed. Alvermann, D. (pp.19-39) New York: Peter Lang.

Lather, P. (2007) Getting lost: Feminist efforts toward a double(d) science. Albany, NY: SUNY.

McLuhan, M. (1964) Understanding Media: The Extensions of Man. New York: McGraw-Hill.

Mead, G.H. (1932) "Science and the Objectivity of Perspectives" in The Philosophy of the Present, La Salle Ill: Open Court.

Pink, S. (2006). Doing visual ethnography: Images, media, and representation in research. London: SAGE Publishing.

Ranciere, J. (1991) The Ignorant Schoolmaster: Five Lessons in Intellectual Emancipation (Trans. Kristin Ross) Stanford: Stanford University Press.

Ryle, G. (1949) The Concept of Mind. Chicago: University Of Chicago Press.

Wertsch, J. (1991) Voices of the Mind: A Sociocultural Approach to Mediated Action. Cambridge: Harvard University Press.

Wittig, M. (1992) "The Trojan Horse" in The Straight Mind and Other Essays (pp6875). Boston: Beacon Press.

\section{Author Biography:}

Suzanne de Castell is Professor in the Faculty of Education, Simon Fraser University. She co-edited Worlds in Play: International Perspectives on Digital Games Research (Peter Lang, 2008) and has recent publications on digital games and education, gender and gameplay, multimodal analysis and informal learning environments. 